\title{
Transitioning from Bipolar II to Bipolar I Disorder in Late Life: Implications for Practice
}

Sir,

The issue of diagnostic validity of Bipolar Disorder (BD)-II continues to divide expert opinion. While some argue for a separate diagnostic status for BD-II based on true genetic breeding, others point out the significant minority who eventually convert to more disabling BD-I to argue against giving $\mathrm{BD}-\mathrm{II}$ a separate diagnostic status. $^{[1,2]}$ Early age of onset has been one of the most consistently replicated risk factors for progression from BD-II to BD-I. ${ }^{[3]}$ We report the case of an elderly lady who converted from a baseline diagnosis of BD-II to BD-I after two decades of illness.

A 60-year-old lady presented to outpatient psychiatry services with the 2-week history of pervasive irritability, increased psychomotor activity, increased self-esteem, pressured speech, and decreased need for sleep. A file review revealed two initial depressive episodes followed by multiple hypomanic episodes occurring at an interval of 2 years, each lasting for an average of 15 days duration. After the first depressive episode, she was initiated on capsule fluoxetine $40 \mathrm{mg}$ which was continued for next 3 years. Later, in 2011, for her second depressive episode, she was stabilized on tablet amitriptyline $100 \mathrm{mg}$ which she was continuing till the index presentation. Based on this information, until the current episode, a lifetime diagnosis of BD-II looked appropriate.

Due to the extreme degree of excitement and aggression, the patient was offered inpatient care. Baseline blood biochemistry, metabolic panel, and imaging study were unremarkable. We made a diagnosis of BD-I - Current Episode Mania with Psychotic symptoms and started her on tablet lithium $600 \mathrm{mg}$ and tablet chlorpromazine $200 \mathrm{mg}$ after stopping amitriptyline. Over the next 2 weeks, she experienced significant improvement with this regimen. The patient was discharged and is maintaining well for the last 3 months.

The present case describes a patient who eventually converted from BD-II to BD-I after two decades of illness onset. Birmaher et al., in two separate longitudinal studies on childhood-onset BD-II (mean follow-up for $2-4$ years), have reported nearly $20 \%-25 \%$ progression to more severe bipolar-I. ${ }^{[4,5]}$ In a 10 -year follow-up study on adults, the authors found a $5 \%-7 \%$ conversion rate of BD-II to BD-I. ${ }^{[6]}$ There are a couple of clinical implications from the index case: first that soft bipolar subtypes with their onset in the fifth decade of life may also eventually convert to BD-I, and second, this conversion may happen even after two decades of illness onset. Some authors have elaborated on the role of behavioral approach system (BAS) which represents a behavioral-motivation system that regulates approach to a range of rewards and safety cues. Individuals with $\mathrm{BD}$, in this model, are believed to be hypersensitive to reward relevant cues, and this has been confirmed in many self-report and behavioral task-based studies. ${ }^{[7]}$ However, it remains to be established whether the BAS sensitivity theory may identify individuals likely to convert to more severe bipolar variants with time. We hope this report spurs further research on the construct validity of a diagnosis of BD-II.

\section{Declaration of patient consent}

The authors certify that they have obtained all appropriate patient consent forms. In the form the patient(s) has/have given his/her/their consent for his/ her/their images and other clinical information to be reported in the journal. The patients understand that their names and initials will not be published and due efforts will be made to conceal their identity, but anonymity cannot be guaranteed.

\section{Financial support and sponsorship}

Nil.

\section{Conflicts of interest}

There are no conflicts of interest.

Ashvini Vengadavaradan, Gopinath Sathyanarayanan, Vikas Menon

Department of Psychiatry, Jawaharlal Institute of Post Graduate Medical Education and Research, Puducherry, India

Address for correspondence: Dr. Vikas Menon, Department of Psychiatry, Jawaharlal Institute of Post Graduate Medical Education and Research, Puducherry - 605 006, India. E-mail: drvmenon@gmail.com

\section{REFERENCES}

1. Cassano GB, Dell'Osso L, Frank E, Miniati M, Fagiolini A, Shear K, et al. The bipolar spectrum: A clinical reality in search of diagnostic criteria and an assessment methodology. J Affect Disord 1999;54:319-28.

2. Andreasen NC, Grove WM, Shapiro RW, Keller MB, Hirschfeld RM, McDonald-Scott P, et al. Reliability of lifetime diagnosis. A multicenter collaborative perspective. Arch Gen Psychiatry 1981;38:400-5. 
3. Alloy LB, Urošević S, Abramson LY, Jager-Hyman S, Nusslock R, Whitehouse WG, et al. Progression along the bipolar spectrum: A longitudinal study of predictors of conversion from bipolar spectrum conditions to bipolar I and II disorders. J Abnorm Psychol 2012;121:16-27.

4. Birmaher B, Axelson D, Strober M, Gill MK, Valeri S, Chiappetta L, et al. Clinical course of children and adolescents with bipolar spectrum disorders. Arch Gen Psychiatry 2006;63:175-83.

5. Birmaher B, Axelson D, Goldstein B, Strober M, Gill MK, Hunt J, et al. Four-year longitudinal course of children and adolescents with bipolar spectrum disorders: The course and outcome of bipolar youth (COBY) study. Am J Psychiatry 2009;166:795-804.

6. Coryell W, Endicott J, Maser JD, Keller MB, Leon AC, Akiskal HS, et al. Long-term stability of polarity distinctions in the affective disorders. Am J Psychiatry 1995;152:385-90.

7. Alloy LB, Abramson LY. The role of the behavioral approach system (BAS) in bipolar spectrum disorders. Curr Dir Psychol Sci 2010;19:189-94.
This is an open access journal, and articles are distributed under the terms of the Creative Commons Attribution-NonCommercial-ShareAlike 4.0 License, which allows others to remix, tweak, and build upon the work non-commercially, as long as appropriate credit is given and the new creations are licensed under the identical terms.

\section{Access this article online}

\begin{tabular}{ll}
\multicolumn{2}{c}{ Access this article online } \\
Quick Response Code: & $\begin{array}{l}\text { Website: } \\
\end{array}$ \\
& www.ruralneuropractice.com \\
& \\
&
\end{tabular}

How to cite this article: Vengadavaradan A, Sathyanarayanan G, Menon V. Transitioning from bipolar II to bipolar I disorder in late life: Implications for practice. J Neurosci Rural Pract 2018;9:277-8.

(c) 2018 Journal of Neurosciences in Rural Practice | Published by Wolters Kluwer - Medknow 